\title{
Female Head, Food Stamps, Ethnicity and Air Pollution: Confounders or Causes of Heart Disease in Texas
}

\author{
Faye Anderson, Najla N. Al-Thani \\ Independent Scholars, Houston, TX, USA \\ Email: andersonfaye7@gmail.com
}

Received 7 April 2016; accepted 21 May 2016; published 24 May 2016

Copyright (C) 2016 by authors and Scientific Research Publishing Inc.

This work is licensed under the Creative Commons Attribution International License (CC BY).

http://creativecommons.org/licenses/by/4.0/

(c) (i) Open Access

\section{Abstract}

One in every four deaths in the United States is attributed to heart disease. While the ethnic variations have not been momentous, the socioeconomic disparities of heart disease incidence need to be further investigated. Moreover, exposure to air pollutants has been documented to cause heart disease. This secondary-data study investigates the effects of air pollutants as well as socioeconomic factors on hospitalization rate of heart disease in Texas. The rates for the five sub-diagnoses of cardiovascular disease, heart attack, stroke, hypertension and heart disease were linked to ozone, fine particulate matter, carbon monoxide, nitrogen dioxide, sulphur dioxide and socioeconomic status factors at the county level. These were college education attainment, households with female heads, percentage of users of food stamps, ethnicities, living near a park and living in houses with severe housing problems. Spatial lag modelling was conducted to estimate the statistical significance of the independent variables on the five sub-diagnoses of heart disease. Fine particulate matter, sulphur dioxide and being African American were significant to all the outcomes. Living in a household with female head was significant to stroke and hypertension. Using food stamps was significant to cardiovascular disease, heart attack and heart disease. Fine particulate matter and sulphur dioxide increase the risk of heart disease by a factor of three to twenty two times, respectively. Whereas low socioeconomic status increases the risk of heart disease by a factor of up to four times. The results of the effect of particulate air and sulphur dioxide pollution among people in low social class especially African Americans. The vicious cycle of heart disease and low socioeconomic status call for societal and policy makers' attention through methodical interventions to address the two significant issues of industrial facilities site allocation and stationary emission resources.

\section{Keywords}

Heart Disease, Female Head, Food Stamps, Sulphur Dioxide, Particulate Matter 


\section{Introduction}

More than 610,000 people die of heart disease in the United States (US) every year. Risk factors include diabetes, obesity, diet, physical activity and excessive alcohol use. It refers to several heart conditions including cardiovascular disease (CVD), heart attack, stroke, hypertension and heart disease [1]. These outcomes have been positively associated to air pollution [2] [3] and negatively related to socioeconomic status (SES) [4] [5].

Levels of air pollutants individually or combined contribute to the adverse cardiac health effects. The five air pollutants of carbon monoxide (CO), nitrogen dioxide $\left(\mathrm{NO}_{2}\right)$, ozone $\left(\mathrm{O}_{3}\right)$, fine particulate matter (particles with aerodynamic diameter $<2.5 \mu \mathrm{m}$, PM2.5) and sulphur dioxide $\left(\mathrm{SO}_{2}\right)$ are especially associated with high heart disease morbidity and mortality. The American Cancer Society cohort estimated that for each $10-\mu \mathrm{g} / \mathrm{m}^{3}$ increase in annual mean exposure to PM2.5, cardiopulmonary mortality was increased by approximately 6\% [6]. Among these air pollutants particulate matter has gained most of the research attention due to the considerable evidence of its adverse health effects [2] [4] [7]-[10]. Risk factors that have been documented to increase the risk of heart disease include age, low educational attainment, presence of pre-existing cardiorespiratory condition [6], diabetes mellitus and smoking [11].

Texas has few of the most severe ozone non-attainment areas in the United States (US). The eight-county Houston-Galveston area (HGA), the nine-county Dallas-Fort Worth (DFW), Beaumont-Port Arthur Area (BPA), the El Paso area, and other metropolitan areas in Texas have a long history of ozone and particulate matter nonattainment. Despite the impressive progress in Texas air quality over the past decade, many challenges persist especially with the recent stricter standards. In addition, the latest technology advances related to oil and gas production in the State has complicated emission inventory activities related to O3 precursors (nitrogen oxides, volatile organic compounds) and other pollutants (e.g.; benzene) [12]. These call for effective methods to develop and execute abatement plans.

Air pollutants and especially $\mathrm{SO}_{2}$ levels decrease with increased distance from the source. Thus, majority of research on its health effects are of small scale [13], which limits our understanding of the spatial deviations of its effect on a regional level [10]. Moreover, associations between heart disease and socioeconomic status have been documented but have seldom been investigated in the same context of exposure to air pollution. Furthermore, the spatial variations of their causal associations have never been investigated to fully understand the interactions and burden associated with heart disease. The objective of this study was to assess the association between heart disease and both air pollution and SES factors in Texas for 2013.

\section{Methods}

Hospital discharge rates by county in Texas, for all ages in 2013 were obtained from the website for the Centers for Disease Control and Prevention (CDC) [14], using International Classification of Diseases Version 9 (ICD-9) codes (presented in Table 1). Observations for $\mathrm{CO}, \mathrm{NO} 2, \mathrm{O} 3, \mathrm{PM} 2.5$ and $\mathrm{SO}_{2}$ were downloaded from the website of the United States Environmental Protection Agency (EPA) [15], and interpolated using ordinary kriging in order to calculate the annual mean for each county in 2013. Ordinary kriging spatially estimates measurements while minimizing error variance [16]. Socioeconomic status variables were collected from the US Census website [17] for the same year. Pearson pair-wise correlations $(\rho)$ were calculated to test for collinearity between the independent variables. Independent variables used were hospital discharge rates for CVD, heart attack, stroke, hypertension and heart disease from CDC; $\mathrm{CO}, \mathrm{NO}_{2}, \mathrm{O}_{3}, \mathrm{PM} 2.5$ and $\mathrm{SO}_{2}$ from EPA; and percentages for college education, female head, food stamp usage, poverty, native origin, Asian origin, African American, Asian, Hispanic, white, living near a park and living with severe housing problems (Table 1). Spatial dependence between the variable was calculated using Moran I. The multivariate spatial regression lag model assessed was: [Overall Rate, Children Rate, Adult Rate] $=\mathrm{W} \gamma+\beta \mathrm{sX}+$ spatial residuals, where $\mathrm{W} \gamma$ is spatially lagged dependent variable for the weights matrix $\mathrm{W}, \beta \mathrm{s}$ is the regression coefficients, and $\mathrm{X}$ is the matrix of independent variables. The Weights matrix stores the pair-wise spatial associations in the dataset [16]. Spatial analyses were performed using the significance level of 0.05 in R version 3.1.1 [18]. ArcMap 10.3.1 [19] was used to generate the maps.

\section{Results}

Figure 1 presents the number of heart disease hospital discharges for each of the five diagnoses where CVD had 
Table 1. List of variables collected and analyzed statistics for this study and their resources.

\begin{tabular}{|c|c|}
\hline Variable & Resource \\
\hline Hospital Discharge Rate for Cardiovascular Disease (ICD-9 codes 390 - 459) & CDC \\
\hline Hospital Discharge Rate for Heart Attack ( ICD-9 code 410) & CDC \\
\hline Hospital Discharge Rate for Stroke (ICD-9 codes $430-434$ or 436 - 438) & CDC \\
\hline Hospital Discharge Rate for Hypertension (ICD-9 codes 401 - 405) & CDC \\
\hline Hospital Discharge Rate for Heart Disease (ICD-9 codes 390 - 398, 402, 404, or 410 - 429) & CDC \\
\hline Annual Average Ambient Concentrations of CO (ppm) & EPA \\
\hline Annual Average Ambient Concentrations of $\mathrm{NO}_{2}(\mathrm{ppb})$ & EPA \\
\hline Annual Average Ambient Concentrations of $\mathrm{O}_{3}(\mathrm{ppm})$ & EPA \\
\hline Annual Average Ambient Concentrations of PM2.5 $\left(\mu \mathrm{g} / \mathrm{m}^{3}\right)$ & EPA \\
\hline Annual Average Ambient Concentrations of $\mathrm{SO}_{2}(\mathrm{ppb})$ & EPA \\
\hline Percentage without 4+ Years College (\%) & US Census \\
\hline Families with Female Head of Household (\%) & US Census \\
\hline Percentage Food Stamp/Supplemental Nutrition Assistance Program Recipients (\%) & US Census \\
\hline Percentage Living in Poverty All Ages (\%) & US Census \\
\hline Percentage of Population with Native Origins (\%) & US Census \\
\hline Percentage of Population of Asian Origins (\%) & US Census \\
\hline Percentage of Population That Is African American (\%) & US Census \\
\hline Percentage of Population of Hispanic Origins (\%) & US Census \\
\hline Percentage of White Population (\%) & US Census \\
\hline Percentage of Population Living Within Half a Mile of a Park & US Census \\
\hline Percentage of Households Living with Severe Housing Problems (\%) & US Census \\
\hline
\end{tabular}

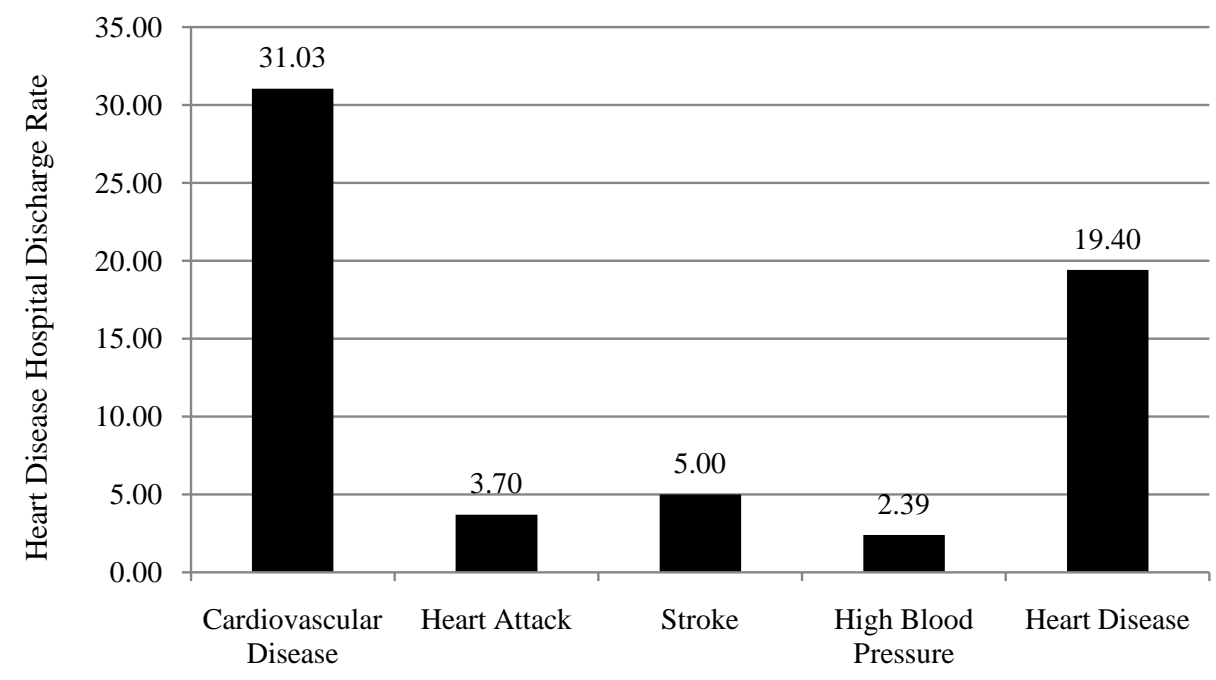

Figure 1. Texas heart disease hospital discharge rates per 10,000 in 2013 (CDC 2015b).

the largest number of 310,335 followed by heart disease $(194,032)$, then stroke $(49,974)$, then heart attack $(37,032)$ and finally hypertension $(23,903)$. Table 2 presents summary statistics for the five air pollutants. Their annual averages for that year were all under the National Ambient Air Quality Standards (NAAQS) and their variations were reasonable. Their kurtosis and skewness estimates did not suggest substantial deviation from normality.

Table 3 presents descriptive statistics for the eleven variables that were selected to represent the socioeconomic 
Table 2. Summary statistics for the five criteria pollutants based on interpolated analyses.

\begin{tabular}{|c|c|c|c|c|c|}
\hline & $\begin{array}{c}\mathrm{CO} \\
(\mathrm{ppm})\end{array}$ & $\begin{array}{l}\mathrm{NO}_{2} \\
(\mathrm{ppb})\end{array}$ & $\begin{array}{c}\mathrm{O}_{3} \\
(\mathrm{ppm})\end{array}$ & $\begin{array}{c}\mathrm{SO}_{2} \\
((\mathrm{ppb})\end{array}$ & $\begin{array}{l}\text { PM2.5 } \\
\left(\mu \mathrm{g} / \mathrm{m}^{3}\right)\end{array}$ \\
\hline Mean & 0.93 & 26.08 & 0.02 & 5.04 & 8.61 \\
\hline Standard Deviation & 0.23 & 4.86 & 0.00 & 0.76 & 1.17 \\
\hline Kurtosis & -1.02 & -0.40 & -0.55 & -0.92 & -0.33 \\
\hline Skewness & 0.28 & 0.08 & -0.15 & -0.24 & 0.55 \\
\hline Minimum & 0.52 & 15.99 & 0.02 & 3.00 & 6.60 \\
\hline Maximum & 1.52 & 39.62 & 0.03 & 6.41 & 12.50 \\
\hline
\end{tabular}

Table 3. Summary statistics for the socioeconomic variables for Texas counties in 2013.

\begin{tabular}{|c|c|c|c|c|c|c|c|c|c|c|c|}
\hline & $\begin{array}{c}\text { Percentage of } \\
\text { Population } \\
\text { without College } \\
\text { Education }\end{array}$ & $\begin{array}{c}\text { Female } \\
\text { Head }\end{array}$ & $\begin{array}{c}\text { Food } \\
\text { Stamp }\end{array}$ & Poverty & Native & Asian & $\begin{array}{c}\text { African } \\
\text { American }\end{array}$ & Hispanic & Caucasian & Park & $\begin{array}{c}\text { Percentage of } \\
\text { Population with } \\
\text { Housing } \\
\text { Problems }\end{array}$ \\
\hline Mean & 82.26 & 17.08 & 15.58 & 18.15 & 0.30 & 0.85 & 6.18 & 32.89 & 58.43 & 18.48 & 14.13 \\
\hline $\begin{array}{l}\text { Standard } \\
\text { Deviation }\end{array}$ & 7.22 & 5.31 & 6.53 & 5.65 & 0.58 & 1.71 & 6.71 & 23.09 & 21.17 & 17.81 & 4.30 \\
\hline Kurtosis & 2.74 & -0.15 & 2.39 & 1.32 & 125.50 & 41.36 & 1.24 & 0.31 & 0.02 & 0.36 & 2.00 \\
\hline Skewness & -1.47 & 0.02 & 1.06 & 0.70 & 9.68 & 5.53 & 1.36 & 1.04 & -0.75 & 1.06 & 0.56 \\
\hline Minimum & 50.60 & 3.40 & 2.50 & 6.60 & 0.00 & 0.00 & 0.00 & 2.20 & 1.20 & 0.00 & 0.00 \\
\hline Maximum & 94.80 & 32.80 & 43.60 & 43.10 & 8.00 & 17.30 & 33.30 & 98.40 & 96.50 & 74.00 & 32.20 \\
\hline
\end{tabular}

status. On average, eighty two percent were without college education, seventeen percent lived in households with female head, sixteen percent used food stamps, eighteen percent were in poverty, eighteen percent lived within half a mile of a park and fourteen percent lived in houses with severe housing problems. On average, about fifty nine percent of the population WAS white, thirty three percent were Hispanic and seven percent were African American.

Figure 2(a) and Figure 2(b) present the spatial distribution for cardiovascular disease and hypertension hospital discharge rates in 2013, respectively. Both rates were higher near large metropolitan areas. The spatial distribution of hypertension hospitalizations is more clustered near Amarillo, Houston, San Antonio, Laredo and El Paso (Figure 2(b)). The spatial distribution of the percentage of households with female head (Figure 2(c)) is scattered with large clusters in the south and west of the State. The spatial distribution of the annual mean $\mathrm{SO}_{2}$ in 2013 (Figure 2(d)) shows the highest concentrations gradually decreasing from the east to the west with a high spot in El Paso (west).

Statistically significant pair-wise associations were high among the health outcomes (Table 4). $\mathrm{SO}_{2}$ was positively associated with CVD and PM2.5. Lacking college education was positively associated with heart attacks, stroke and heart disease. Living in a household with female head and using food stamps were positively associated with hypertension. Percentage of African Americans was positively associated with $\mathrm{SO}_{2}$ and PM2.5 whereas percentage of Caucasian was positively associated with stroke and negatively associated with hypertension.

The statistically significant spatial regression coefficients are presented in Table 5. For every $1 \mu \mathrm{g} / \mathrm{m}^{3}$ increase in PM2.5, CVD rate increased by 5.21, heart attack rate increased by 2.77 , stroke rate increased 4.52, hypertension rate increased by 2.47 and heart disease rate increased by 3.74 . For every $1 \mathrm{ppm} \mathrm{SO}_{2}$ increase in $\mathrm{SO}_{2}$, CVD rate increased by 21.76 , heart attack rate increased by 5.04 , stroke rate increased by 8.43 , hypertension increased by 3.63 and heart disease increased by 14.90 . For every 1 household with female head increase, stroke rate increased by 0.74 and hypertension rate increased by 0.46 . For every 1 household rise in food stamp use, CVD rate increased by 3.67, heart attack rate increased by 0.50 and heart disease rate increased by 1.45 . An increase in African American by one percentage, increased all health outcomes from 0.31 (hypertension) to 1.63 (CVD). An increase in Caucasians by one percent increased CVD rate by 0.33 . Lastly, raising college education 


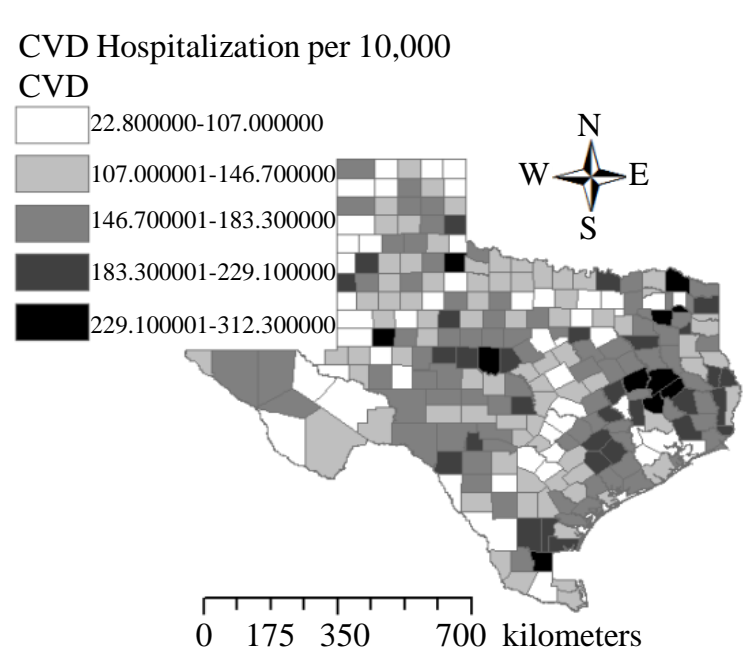

(a)

Percentage of Households with Female Head Female Head

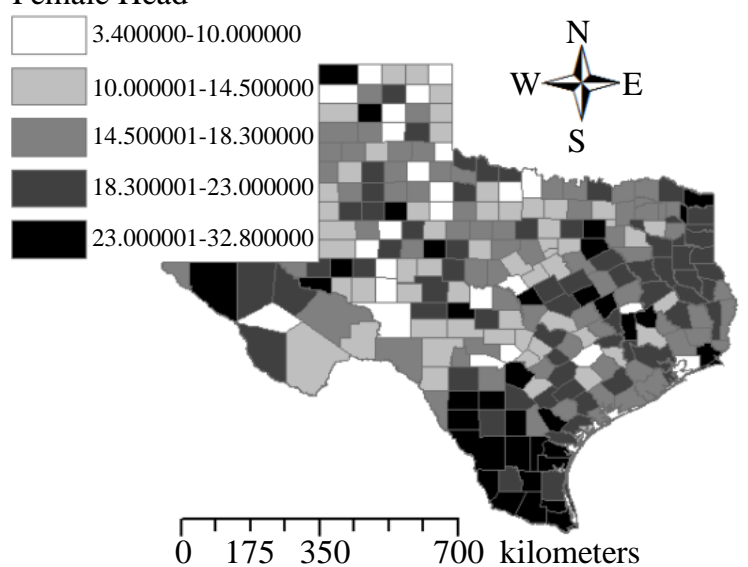

(c)
Hypertension Hospitalization per 10,000

HBP

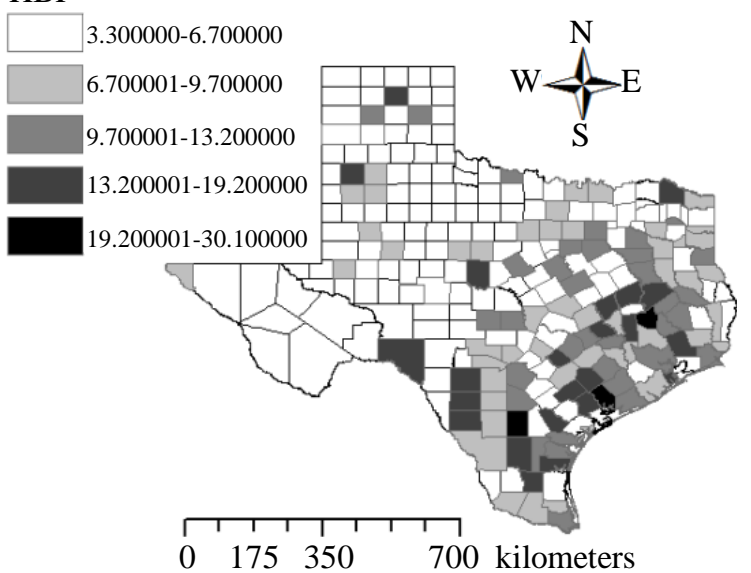

(b)

Annual Average for SO2 (2013)

$\mathrm{SO} 2$

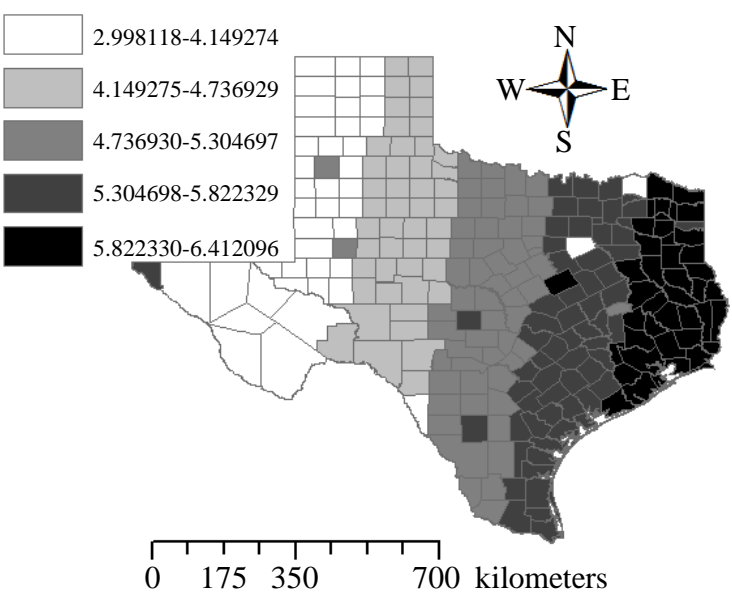

(d)

Figure 2. Heart disease hospitalizations and annual averages of PM2.5 and $\mathrm{SO}_{2}$ for Texas counties for 2013. (a) Cardiovascular disease hospitalizations rate per 10,000 in 2013. (b) Hypertension hospitalizations rate per 10,000 in 2013. (c) Percentage of households with female head in 2013. (d) $\mathrm{SO}_{2}$ annual averages for 2013 (1-hr).

by one percent increased heart attack rate by 0.36 , stroke by 0.34 and heart disease by 1.37 .

In summary, the recorded hospital discharge rates for cardiovascular disease, heart attack, stroke, high blood pressure and heart disease were 31.03, 3.70, 5.00, 2.39 and 19.40; respectively. In those counties, more than 82\% of the population did not have college education, $17 \%$ of the households had female heads, more than $15 \%$ were on food stamps and more than $18 \%$ of the population was in poverty. More than $18 \%$ were near a park and more than $14 \%$ lived in houses with severe housing problems. As for ethnicities, more than $58 \%$ were Caucasian, $32 \%$ Hispanics, and 6\% African American. High blood pressure was more positively associated with percentage of households with female head than those on food stamps. None of the five sub-diagnoses of heart disease had significant pair-wise association with either $\mathrm{SO}_{2}$ or PM2.5. However, both pollutants as well as being African American were significant to each of the health outcome. Being Hispanic was not significantly associated with any of the five health outcomes.

\section{Discussion}

The current challenges in identifying the precise causes of heart disease disparities have been addressed by few 
Table 4. Statistically significant pair-wise associations between the five health outcomes and the independent variables (p-value < 0.05).

\begin{tabular}{|c|c|c|c|c|c|c|c|c|c|}
\hline & CVD & $\begin{array}{c}\text { Heart } \\
\text { Attack }\end{array}$ & Stroke & $\begin{array}{l}\text { High Blood } \\
\text { Pressure }\end{array}$ & Heart Disease & $\mathrm{SO}_{2}$ & PM2.5 & $\begin{array}{c}\text { Female } \\
\text { Head }\end{array}$ & $\begin{array}{l}\text { Food } \\
\text { Stamps }\end{array}$ \\
\hline Cardiovascular Disease & 1.00 & & & & & & & & \\
\hline Heart Attack & 0.66 & 1.00 & & & & & & & \\
\hline Stroke & 0.80 & 0.59 & 1.00 & & & & & & \\
\hline High Blood Pressure & 0.51 & 0.29 & 0.31 & 1.00 & & & & & \\
\hline Heart Disease & 0.96 & 0.69 & 0.70 & 0.50 & 1.00 & & & & \\
\hline $\mathrm{SO}_{2}(\mathrm{ppb})$ & 0.32 & -0.02 & 0.30 & 0.04 & 0.25 & 1.00 & & & \\
\hline PM25 $\left(\mu \mathrm{g} / \mathrm{m}^{3}\right)$ & 0.07 & -0.26 & 0.01 & -0.21 & -0.01 & 0.77 & 1.00 & & \\
\hline $\begin{array}{c}\text { Percentage of } \\
\text { Population without } \\
\text { College Education }\end{array}$ & 0.29 & 0.41 & 0.33 & 0.29 & 0.28 & 0.00 & -0.23 & 0.29 & 0.46 \\
\hline Female Head & 0.14 & -0.09 & -0.01 & 0.34 & 0.06 & 0.21 & 0.22 & 1.00 & 0.71 \\
\hline Food Stamp & 0.23 & 0.13 & 0.12 & 0.32 & 0.16 & 0.14 & 0.02 & 0.71 & 1.00 \\
\hline African American & 0.18 & -0.07 & 0.16 & 0.08 & 0.14 & 0.60 & 0.61 & 0.33 & 0.08 \\
\hline Caucasian & 0.20 & 0.16 & 0.32 & -0.27 & 0.22 & 0.22 & 0.17 & -0.56 & -0.61 \\
\hline
\end{tabular}

Table 5. Statistically significant (p-value < 0.05) coefficients from the multivariate spatial regression lag model.

\begin{tabular}{cccccc}
\hline Dependent Variable & $\begin{array}{c}\mathrm{PM} 2.5 \\
\left(\mu \mathrm{g} / \mathrm{m}^{3}\right)\end{array}$ & $\begin{array}{c}\mathrm{SO}_{2} \\
(\mathrm{ppb})\end{array}$ & Female Head & Food Stamp & $\begin{array}{c}\text { African American } \\
\text { Caucasian }\end{array} \begin{array}{c}\text { Percentage of } \\
\text { Pollation without } \\
\text { College Education }\end{array}$ \\
\hline Cardiovascular Disease & 5.21 & 21.76 & & 3.67 & 0.63 \\
Heart Attack & 2.77 & 5.04 & & 0.30 & 0.65 \\
Stroke & 4.52 & 8.43 & 0.74 & 0.36 & 0.31 \\
High Blood Pressure & 2.47 & 3.63 & 0.46 & 1.45 & 1.11 \\
\hline
\end{tabular}

opinions. For this study in Texas, four factors persist: exposure to PM2.5, exposure to $\mathrm{SO}_{2}$, socioeconomic status (female head, food stamps, college education) and ethnicity (being African American). These finding are the first of this nature in general and for Texas in particular.

Contrasting the strongly associated factors of living in a household with female head and using food stamps $(\rho=0.71$ ), shows that being on food stamps has a greater influence on heart disease rates in Texas (increase heart rate from 0.50 to 3.67 per 10,000). Although poverty and being on food stamps are mutually exclusive [17], it seems that the latter puts the at-risk-population deeper in poverty and entails higher risk of heart disease. As for college education, it was positively associated to three of the sub-diagnoses of heart disease, but had higher association to using food stamps than living in a household with female head. This supports the previous findings and points to possible confounding of necessary life-style changes that are impacted by lower educational attainment.

Studying heart disease hospitalization rate racial disparities showed that being African American is positively associated to the five sub-diagnoses. The data analysed cannot determine if this strong relationship is causal or of confounding nature. Nevertheless, the pair-wise associations between being African American and the two significant pollutants (PM2.5 and $\mathrm{SO}_{2}$ ) point to economic factors related to living in cheaper neighbourhoods, which coincide with locations that are favoured by such facilities [20]. This economic elucidation can also explain the impact of lower educational attainment and being on food stamps on heart disease hospitalization rate.

The association between PM2.5 and $\mathrm{SO}_{2}$ and heart disease expressed as the rate increase per 10,000 in hospital admissions for a unit increase in PM2.5 and $\mathrm{SO}_{2}$ levels exceed most of the documented associations in the US and overseas [21]. The strong positive association between PM2.5 and $\mathrm{SO}_{2}(\rho=0.77)$ suggests that industrial 
pollution is a major source of fine particulate matter in Texas and that anthropogenic sources such as traffic are minor ones [10]. This can be explained by the high total toxic release per capita in Texas that exceeds that for the national [22] and it contradicts the claims that controlling the anthropogenic mobile sources in Texas is of more significance than controlling the stationary industrial sources [23].

\section{Strengths and Limitations}

This is the first study to combine the five main diagnoses of heart disease as well as two major factors (air pollution and SES). The results of this research suggest that the number and distribution of PM2.5 and $\mathrm{SO}_{2}$ monitors in Texas are adequate to detect significant links between exposure and the five health outcomes [24]. While the annual averages do not reflect within year temporal and/or spatial variations in the association, the analyses captured some of the significant relationships between heart disease and both air pollution and SES. Moreover, while the data did not allow for investigation of intra-county variations, it allowed for an overall depiction of the relationships between heart disease and air pollution as well as SES, which are of significant impact for policy makers and researchers to quantify and mitigate the burden of heart disease.

The downloaded heart disease data did not include important possible confounders such as age, gender, or lifestyle factors. Lastly, because the discharge data reporting is voluntary for hospitals, heart disease hospitalizations may also be under-represented based on hospital reporting characteristics and data extraction and coding processes used in each location.

\section{Implications for Policy Makers}

The environmental agency for Texas is the Texas Commission on Environmental Quality (TCEQ). It has developed a long list of State Implementation Plans (SIP) and revisions through the air quality management process entailing air monitoring, modelling, planning, rule-making, control strategy, permitting, and inventorying emissions. TCEQ SIPs ensure that The State of Texas is responsible for developing the right plans to comply with the Clean Air Act requirements through the achievement of the NAAQS. As such, SIPs must be continually updated and revised to reflect changes in NAAQS or air quality monitoring data. The steps that are usually followed to develop an SIP are: determining emissions, developing strategy, determining emission changes, modelling to determine changes in air quality, comparison to NAAQS, adjustment of strategy and re-analysis, rulemaking to implement strategy, adoption of rules using state process and minimum federal public participation requirements (40 CFR Part 51), submission to the United States Environmental Protection Agency (EPA), and EPA rule-making. In order to understand the cause of non-attainment, develop control strategies to reach attainment, demonstrate that the selected strategies will lead to attainment and assess amount of progress made towards reaching NAAQS, TCEQ uses emission inventories, monitoring data, and air quality models. The State process includes revised SIP, public notices for comment period, public hearings, responding to comments, State-required legislative review, formal adoption, and SIP submittal. The stakeholders of the SIPs development process include federal, state, and local governments; industry; small businesses; environmental groups; and citizens of the state. An SIP revision takes from 18 months to few years and if a revised SIP is not submitted or disapproved, sanctions and other punitive measures are applied [25]. The non-attainment designation in Texas is estimated to cost billions of dollars annually spent on consultation with local stakeholders, health benefits, and cost of implementation. Cost are positively associated with the severity of non-attainment status due to the longer period of time required for abatement. In Texas, majority of SIP revisions were developed for the four areas of the State that have been designated non-attainment for ozone at various times since 1990: DFW, HGA, BPA, and the El Paso area [26].

The NAAQS standard for ozone set in 1997 was $0.08 \mathrm{ppm}$ was revised to $0.075 \mathrm{ppm}$ in 2008 then to 0.070 ppm in 2015 (primary and secondary). The stricter standards resulted in more areas being more likely subject to additional permitting and emissions control requirements. With the decrease in time lapse between the newer standards, the cycle of air quality management process has become more complex, more intense, and more expensive. Despite the efforts exerted to manage air quality in the State, the associations between air pollutant levels and health outcomes have not been addressed in a conclusive manner. This is translated in the negligence of the impact on public health in the process of developing, revising and implementing air quality management processes. Special attention needs to be paid to the permitting of industrial facilities in residential or industrial-to-be locations. 


\section{References}

[1] CDC (2015) Heart Disease Facts. http://www.cdc.gov/heartdisease/facts.htm

[2] Anderson, F., et al. (2014) Spatiotemporal Analysis of the Effect of Ozone and Fine Particulate on CVD Emergency Room Visits in Harris County, Texas. Open Journal of Air Pollution, 3, 87-99. http://dx.doi.org/10.4236/ojap.2014.34009

[3] Wong, T.W., et al. (2002) Associations between Daily Mortalities from Respiratory and Cardiovascular Diseases and Air Pollution in Hong Kong, China. Occupational and Environmental Medicine, 59, 30-35. http://dx.doi.org/10.1136/oem.59.1.30

[4] Anderson, F. (2016) Assessing the Association between Heart Attack, High Blood Pressure, and Heart Disease Mortality Rates and Particulate Matter and Socioeconomic Status Using Multivariate Geostatistical Model. Occupational Diseases and Environmental Medicine, 4, 8-15. http://dx.doi.org/10.4236/odem.2016.41002

[5] Laurent, O., et al. (2007) Effect of Socioeconomic Status on the Relationship between Atmospheric Pollution and Mortality. Journal of Epidemiology and Community Health, 61, 665-675. http://dx.doi.org/10.1136/jech.2006.053611

[6] Pope, C.A., 3rd, et al. (2002) Lung Cancer, Cardiopulmonary Mortality, and Long-Term Exposure to Fine Particulate Air Pollution. JAMA, 287, 1132-1141. http://dx.doi.org/10.1001/jama.287.9.1132

[7] Brunekreef, B. and S.T. Holgate (2002) Air Pollution and Health. The Lancet, 360, 1233-1242. http://dx.doi.org/10.1016/S0140-6736(02)11274-8

[8] Anderson, F., et al. (2015) Age, Race and Gender Spatiotemporal Disparities of COPD Emergency Room Visits in Houston, Texas. Occupational Diseases and Environmental Medicine, 3, 1-9. http://dx.doi.org/10.4236/odem.2015.31001

[9] Anderson, F. (2016) Application of Multivariate Geostatistics in Environmental Epidemiology: Case Study from Houston, Texas. Journal of Geoscience and Environmental Protection, 4, 110-115.

[10] Anderson, J., et al. (2016) The Influence of Air Pollutants and Socioeconomic Status on Asthma in Texas [in Press].

[11] Zanobetti, A. and J. Schwartz (2001) Are Diabetics More Susceptible to the Health Effects of Airborne Particles? American Journal of Respiratory and Critical Care Medicine, 164, 831-833. http://dx.doi.org/10.1164/ajrccm.164.5.2012039

[12] Allen, D., E. McDonald-Buller, and G. McCaughey (2015) State of the Science of Air Quality in Texas: Scientific Findings from the Air Quality Research Program (AQRP). Report for the Period 2010-2015.

[13] Smargiassi, A., et al. (2009) Risk of Asthmatic Episodes in Children Exposed to Sulfur Dioxide Stack Emissions from a Refinery Point Source in Montreal, Canada. Environmental Health Perspectives, 117, 653-659. http://dx.doi.org/10.1289/ehp.0800010

[14] CDC (2015) Interactive Atlas of Heart Disease and Stroke.

[15] EPA (2016) AirData. http://aqsdr1.epa.gov/aqsweb/aqstmp/airdata/download_files.html\#Annual

[16] Fischer, M.M. and A. Getis (2009) Handbook of Applied Spatial Analysis: Software Tools, Methods and Applications. Springer, Berlin.

[17] Census (2011) American FactFinder. http://factfinder.census.gov/faces/nav/jsf/pages/index.xhtml

[18] Core, R. (2014) R: A Language and Environment for Statistical Computing.

[19] ESRI (2015) ArcMap 10.3.1. Redlands.

[20] Mohai, P., D. Pellow, and J.T. Roberts (2009) Environmental Justice. Annual Review of Environment \& Resources, 34, 405-430. http://dx.doi.org/10.1146/annurev-environ-082508-094348

[21] Sunyer, J., et al. (2003) The Association of Daily Sulfur Dioxide Air Pollution Levels with Hospital Admissions for Cardiovascular Diseases in Europe (The Aphea-II study). European Heart Journal, 24, 752-760. http://dx.doi.org/10.1016/S0195-668X(02)00808-4

[22] Anderson, F. and N. Al-Thani (2016) Case Study: Reviewing Methods of Assessing Community Adaptive Capacity for Jefferson County, Texas. American Journal of Climate Change, 5, 8-14. http://dx.doi.org/10.4236/ajcc.2016.51003

[23] Liu, S. and K. Zhang (2015) Fine Particulate Matter Components and Mortality in Greater Houston: Did the Risk Reduce from 2000 to 2011? Science of the Total Environment, 538, 162-168. http://dx.doi.org/10.1016/j.scitotenv.2015.08.037

[24] Anderson, F. (2014) Multivariate Geostatistical Model for Groundwater Constituents in Texas. International Journal of Geosciences, 5, 1609-1617. http://dx.doi.org/10.4236/ijg.2014.513132

[25] EPA (2005) Emissions Inventory Guidance for Implementation of Ozone and Particulate Matter National Ambient Air Quality Standards (NAAQS) and Regional Haze Regulations.

[26] CAPCOG (2015) The Potential Costs of an Ozone Nonattainment Designation to Central Texas. 